\title{
Numerical behaviour of composite K-joints subjected to combined loading and corrosive environment
}

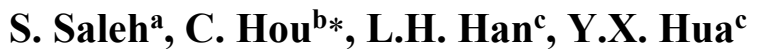 \\ ${ }^{a}$ Department of Civil Engineering, University of Asia Pacific, Dhaka, Bangladesh

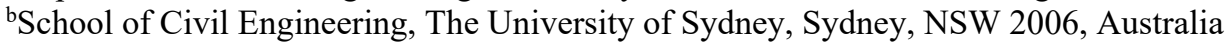 \\ ${ }^{\mathrm{c}}$ Department of Civil Engineering, Tsinghua University, Beijing, 100084, China \\ *corresponding author, e-mail address: chao.hou@sydney.edu.au
}

\begin{abstract}
Concrete filled steel tubular (CFST) truss structures have been adopted in various infrastructures worldwide for the past several decades. Application of CFST truss is sometimes more prevalent in areas where harsh marine environment with chloride corrosion limits the design life of the structures. Design of connections is one of the most complicated issues in CFST truss structures, which becomes even more critical when corrosion induces section loss in the outer steel tube. Improved design in terms of economy and durability needs to be suggested based on rational research on typical composite connections in corrosive environment, whilst such research is yet limited to date. This paper thus attempts to study the behaviour of circular CFST K-joints under the combined effects of long-term loading and corrosion. A finite element analysis (FEA) model is presented and verified against existing test results. The model is then utilized to perform mechanism analysis of CFST K-joints under various loading and corrosion situations. Failure modes, detailed propagation of yield and stress distribution between materials are investigated. Finally, a full range analysis of the load-deformation characteristics is carried out for various corrosion situations, with the corresponding joint strength and ductility predicted.
\end{abstract}

Keywords: CFST K-joints, chloride corrosion, FEA modelling, full-range analysis.

\section{Introduction}

Concrete filled steel tubes (CFST) are becoming more and more predominant in various fields of structural engineering from the latter part of the $20^{\text {th }}$ century, due to the advantages offered by such composite elements. As effective confinement between the inner core concrete and the outer steel tube can exploit structural advantages of both materials, CFST structures can achieve improved behaviour compared to hollow tubular sections, including greater cross-sectional strength, better fire and seismic resistance, and enhanced ductility [1-4]. In addition, the ability to cover longer spans in bridges and create larger column-free area in buildings has made composite materials a popular choice in modern construction. Among these, the application of CFST truss structures has been found practical in offshore environment where harsh marine condition and chloride corrosion often limits the service life of structures, as shown in the offshore tower application displayed in Fig. 1. Design of the CFST tubular connections in corrosive environment thus becomes one of the

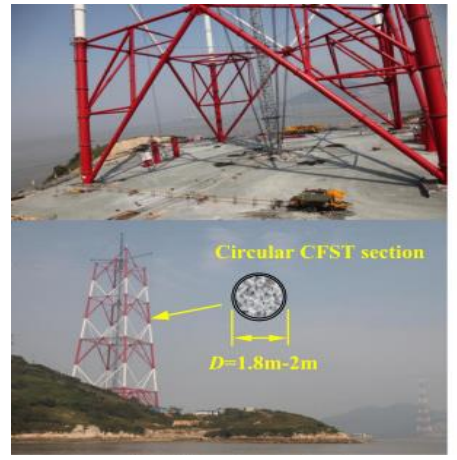

(a) CFST tower in construction

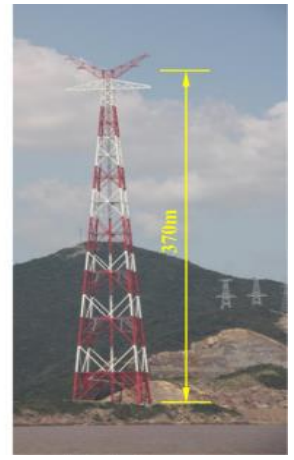

(b) Tower in use
Fig. 1. Use of CFST members in an offshore electric transmission tower [2] 
most critical issues in such practice. Research gap in this area indicates the need for rational investigation.

Many researchers have conducted studies on the performance of single composite members subjected to long-term loading and chloride corrosion [5-8]. Previous studies generally revealed that CFST members exhibited much better performance compared to hollow steel tubular sections as inward buckling can be avoided due to the presence of core concrete in the former. CFST specimens were found to yield excellent structural performance as local buckling can be delayed and load redistribution can be reduced by corrosion along the composite cross-section. Meanwhile, the confinement of outer steel on the core concrete was found to be severely affected by corrosion, leading to the deterioration of both strength and ductility in circular CFST columns. Besides these, scientific research regarding the behaviour of composite joints in corrosive environment is still limited, which requires special attention since several dominating parameters, such as $\beta, \gamma$ and $\tau$, are usually affected during the corrosion process $[9,10]$.

The current work thus presents the behaviour of circular CFST K-joints under combined loading and chloride corrosion. A finite element analysis (FEA) model is established and verified against previous experimental data. The model is then used to analyse the joint strength and mechanism under different loading and corrosion conditions. Finally, full range load versus deformation behaviour and stress distribution under various corrosion conditions have been investigated.

\section{Finite element analysis modelling}

A FEA model of CFST K-joint was built based on the finite element package ABAQUS, which takes into consideration both the sustained loading and the effects of chloride corrosion. Dimensions of the joint samples are adopted from previous experimental studies [11].The influence of sustained loading and corrosion has been simulated by modifying the material properties and adopting the 'Model change, remove' interaction in ABAQUS.

\subsection{Material properties}

Two different types of material properties were chosen for the tube steel and the endplate steel. An elastic-plastic stress-strain model containing five stages [12] was implemented to define the constitutive behaviour of the tube steel. Reasonable values for the modulus of elasticity and the Poisson's ratio $\left(2 \times 10^{5} \mathrm{~N} / \mathrm{mm}^{2}\right.$ and 0.3 respectively) were adopted. The endplates were assumed to be rigid with Young's Modulus of $10^{12} \mathrm{~N} / \mathrm{mm}^{2}$ and Poisson's ratio of $10^{-4}$.

Cubic compressive strength of concrete was chosen as $45 \mathrm{~N} / \mathrm{mm}^{2}$. As proposed in [13], two different types of material properties were considered for core concrete under short-term and long-term sustained loading, with damage plasticity models implemented to reflect the confinement behaviour. Effects of time dependent factors such as shrinkage and creep were taken into consideration based on the research reported in [6] and [13].

\subsection{Configuration of the CFST K-joint}

Real size K-joints used in bridges and arch trusses were considered in this research. CFST6 in [11] with a brace thickness of $6 \mathrm{~mm}$ was chosen, where the chord was infilled with concrete while the braces were hollow.

\subsection{Meshing}

The steel tube is modelled using 8-node 3-D solid elements with reduced integration (C3D8R) to account for its effective thickness loss due to corrosion. Other components of the $\mathrm{K}$-joint such as the core concrete and rigid endplates are also modelled using this type of
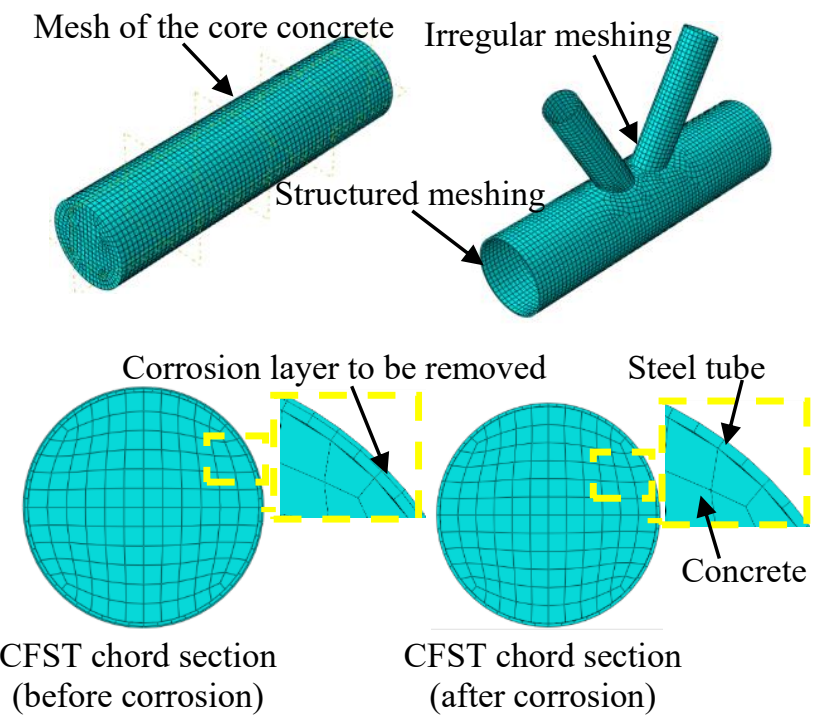

Fig. 2. Schematic view of the FEA modelling

element. As CFST K-joint is relatively complex in geometry, suitable meshing technique is 
essential for the convergence and accuracy of the simulation. In order to achieve proper element shape, structured meshing technique is adopted where possible. However, sweeping meshing technique was applied along the connection zone where two inclined brace tubes intersect with the chord tube, as it was too complex to assign structured meshing due to the irregularity of the plane (Fig. 2). Appropriate mesh density was identified by means of a mesh convergence study, which yield reliable outcome within reasonable computation time.

\subsection{Boundary conditions and interfaces}

Composite K-joint models were developed based on the boundary conditions adopted in previous research such as $[11,14,15]$. The Kjoints investigated in this paper were subjected to axial static loading. Three different boundary conditions commonly seen in practice were evaluated, i.e., (1) loading at the chord, (2) loading at the compressive brace and (3) loading at the tensile brace. The boundary conditions are clearly depicted in Fig. 3.

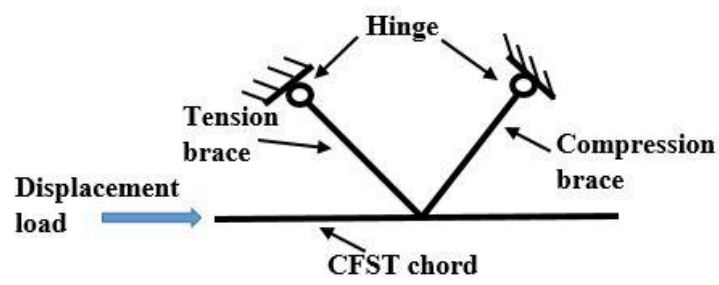

Boundary condition-1

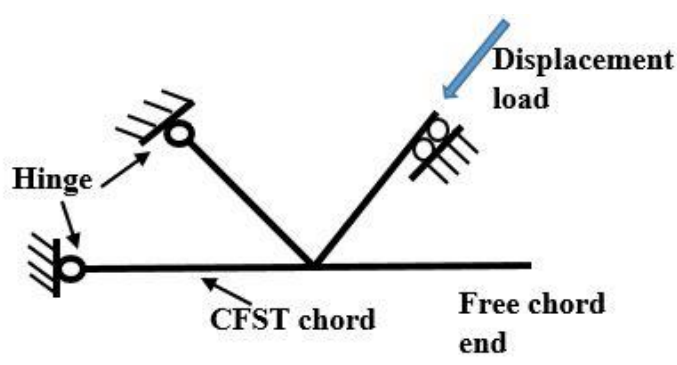

Boundary condition-2

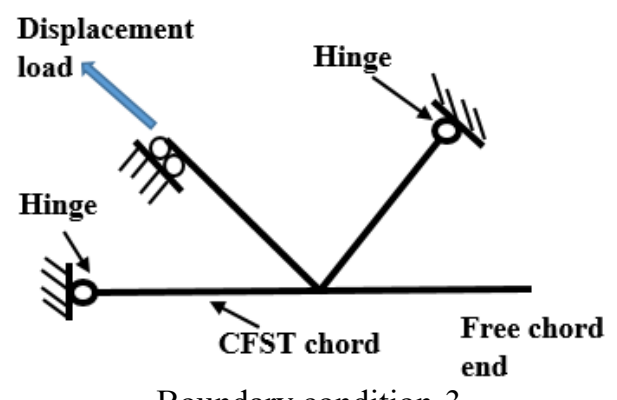

Boundary condition-3

Fig. 3. The considered typical boundary conditions
The interface properties between the steel tube and the core concrete were created by two matching surfaces, which can be separated from each other without any penetration [12], i.e., 'Hard contact' in the normal direction and 'Coulomb friction' model in the tangential direction. Tie constraints were created between the joint material and the loading plates.

\subsection{Simulation of combined corrosion}

As corrosion is a complex and uncertain natural phenomenon, numerical models can seldom be able to replicate the corrosion effects accurately [16]. Therefore, for the sake of simplicity, it is suggested to consider corrosion as a time dependent process which occurs at a constant rate and poses a long-term uniform effect on the outer steel [6-8]. The whole corrosion process is applied to the FE model in four steps. Firstly, partitioning the corrosion affected member and defining the corrosion region; secondly, meshing of the steel tube according to the corrosion thickness; thirdly, applying a separate 'corrosion step' in which the corrosion region will be deactivated; and fourthly, adoption of the modified stress-strain relation to reflect the change of confinement between the steel and concrete due to corrosion. Updated stress-strain relation was implemented by using reduced thickness and diameter of the chord.

\section{Verification of the FEA model}

Two approaches were used for the verification of the model: 1) comparison of the load-displacement relations, and 2) comparison of the failure modes.

The axial load $(N)$ versus axial displacement ( $\Delta$ ) of CFST chord between the experimental results in [11] and the simulated FEA model was compared in Fig. 4, where reasonable agreement is achieved. It should be noted that, though the chord stiffness values are very similar, the FEA model was found to have about $10 \%$ larger ultimate strength compared to the test results. This mainly attributes to the fact that the effects of welding in brace-chord intersection area was not accounted for in the FEA modelling. Comparison of the predicted and observed failure modes for CFST K-joint specimen is shown in Fig. 5. As can be seen, simulation of FEA model showed outward local buckling in the compression brace, and a bulge 
was formed near the connection area, similar to that obtained from test results.

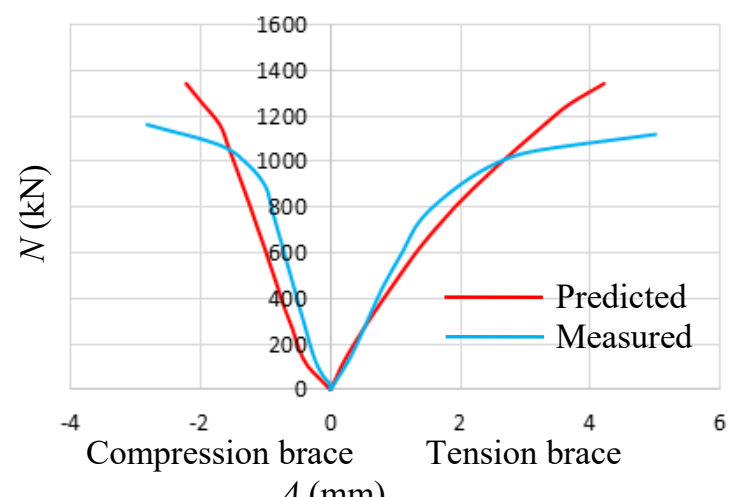

Fig. 4. Comparison of the $N-4$ relations

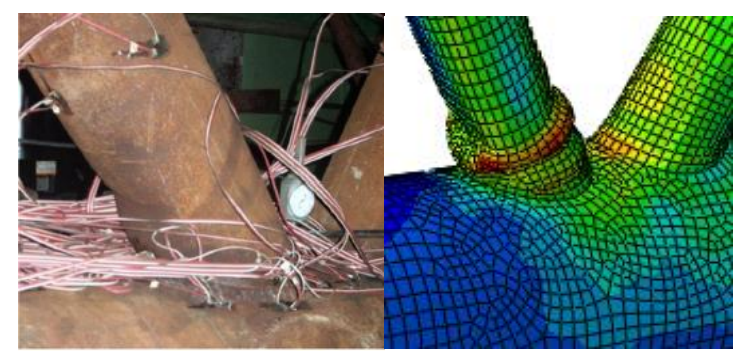

Fig. 5. Comparison of the observed and predicted failure modes

Based on the above comparisons, it can be concluded that the FEA modelling is well capable of capturing reasonable predictions for the structural behaviour of CFST K-joints. The verified FEA model is then utilized to perform the analytical behaviour of CFST K-joints under sustained loading and chloride corrosion.

\section{Analytical behaviour}

\subsection{Typical failure modes}

As the infilled concrete improves the resistance of the chords in CFST K-joints, the composite chord is no longer the weaker part. Different modes of failure were detected depending on various boundary conditions. Typically, three failure modes have been observed in this study, as depicted in Fig. 6.

\section{(a) Mode A: Chord plastification}

This mode is observed when moderate load is applied at the chord. A noticeable region of the chord reaches plastic stage at the chor-brace intersection area, where the corresponding Mises stress is found to be around $431 \mathrm{MPa}$ (Fig. 6a). Mises stress at the braces remains in a range of 280-340 $\mathrm{MPa}$, with no considerable local failure. The outer surface of the infilled concrete develops a maximum compressive stress of $58 \mathrm{MPa}$ at the area of chord plastification. The well-known chord inward buckling is avoided due to the inner support of core concrete, which leads to improved joint behaviour compared to CHS joints.

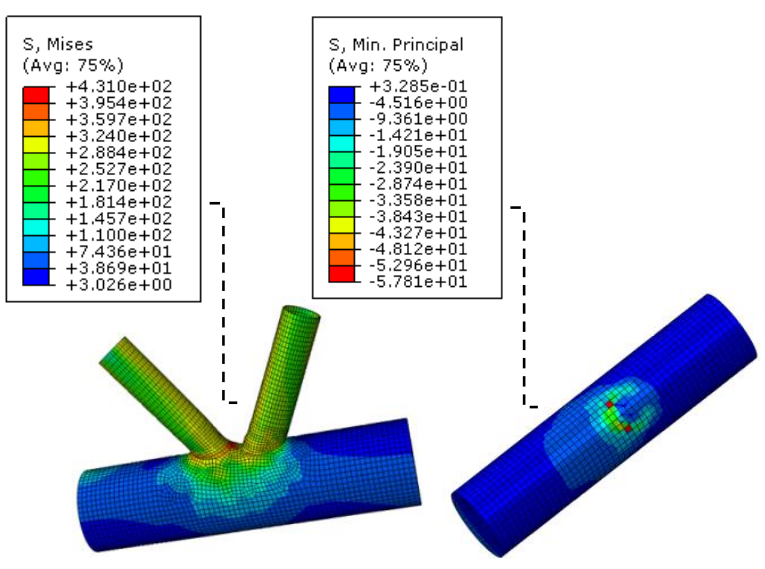

(a1) overall view of the joint (a2) inner concrete (a) Mode A: Chord plastification

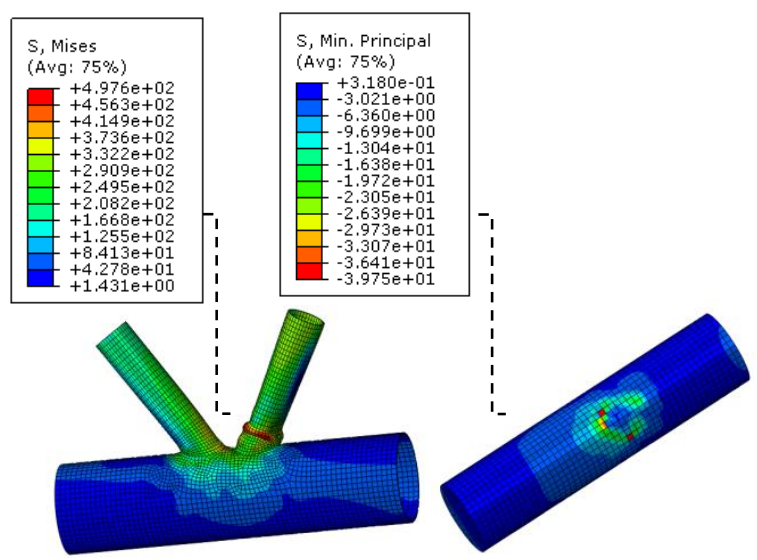

(b1) overall view of the joint (b2) inner concrete

(b) Mode B: Chord plastification combined with local buckling of the brace

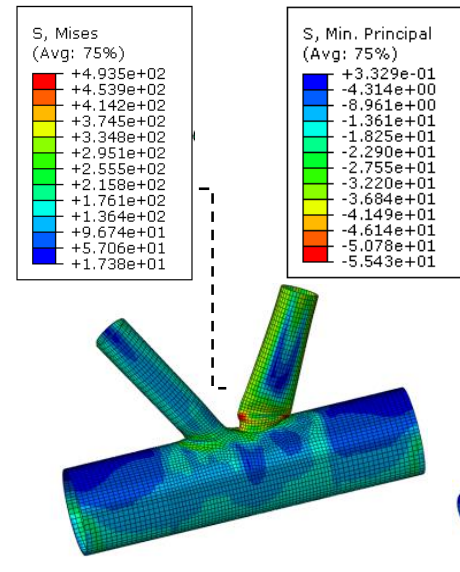

(c1) overall view of the joint

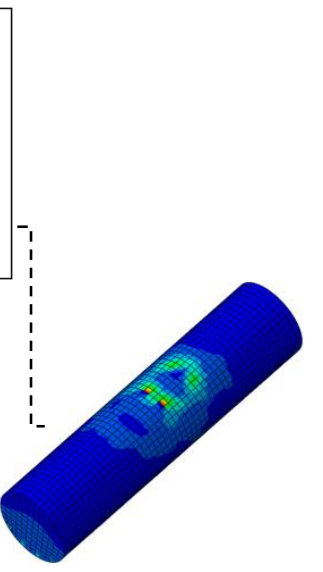

(c2) inner concrete (c) Mode C: Immature local buckling of the brace

Fig. 6. Typical failure modes of CFST K-joints and the corresponding stress distribution 
(b) Mode B: Chord plastification combined with local buckling of the brace

This combined failure mode was obtained when significant load is applied at the chord end. The chord tube at the connection area reaches plastic state at first, prominent local buckling is then noticed at the compression brace near the intersection (Fig. 6b). Obvious stress concentration at the local buckling region is found, with the hollow brace failing at Mises stress of $497 \mathrm{MPa}$. At the time of compression brace failure, critical zones of the chord tube and the tension brace remain at moderate stress level (310-350 MPa). Stresses at the outer region of core concrete is relatively lower than Mode A (around $40 \mathrm{MPa}$ ), whilst the inner region is unaffected.

(C) Mode C: Immature local buckiling of the brace

Under this mode, a small region at the tension brace near the connection area enters plasticity at the early stage of loading. With the loading process continues, localized stresses at the compression brace starts to accumulate and yield begins around the connection area. Unlike the first two modes, the entire compression brace fails due to local buckling with huge plastic deformation whilst most of the chord region remains elastic (Fig 6c). Maximum Mises stress at the critical brace location is found to be around $493 \mathrm{MPa}$. Stress along the intersection remains elastic (maximum 310 $\mathrm{MPa}$ ). Outer region of the concrete gains a compressive stress of about $55 \mathrm{MPa}$ near the critical compression brace region. The stress level at the outer concrete surface is very similar to Mode A and about 38\% larger compared to Mode B.

Overall, the failure Mode C and Mode B is similar except for the chord plastification phenomenon. Compared with CHS joints, the composite chords are strong enough so that the compression braces tend to buckle first.

\subsection{Yield propagation behaviour}

The spread of yield region was obtained in terms of the stress development from the detailed FE analysis. It was obtained that in the connection area, stress in the core concrete and the steel tube increases significantly over time while that in the failure region remains almost constant. Maximum Mises stress in the steel tube escalates gradually from 128 to $421 \mathrm{MPa}$ over the period of loading (Fig. 7a). Similarly, concrete along the intersection gains $24 \mathrm{MPa}$ stress at the beginning and gradually peaks to around $80 \mathrm{MPa}$, reaching its ultimate strength during the loading.

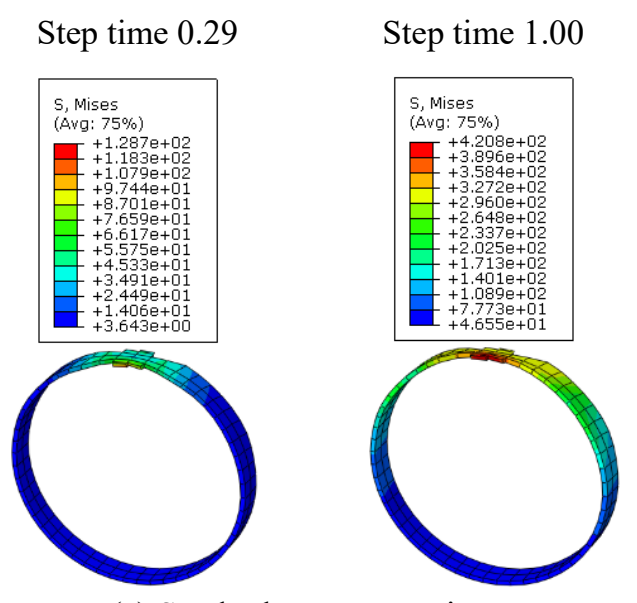

(a) Steel tube at connection

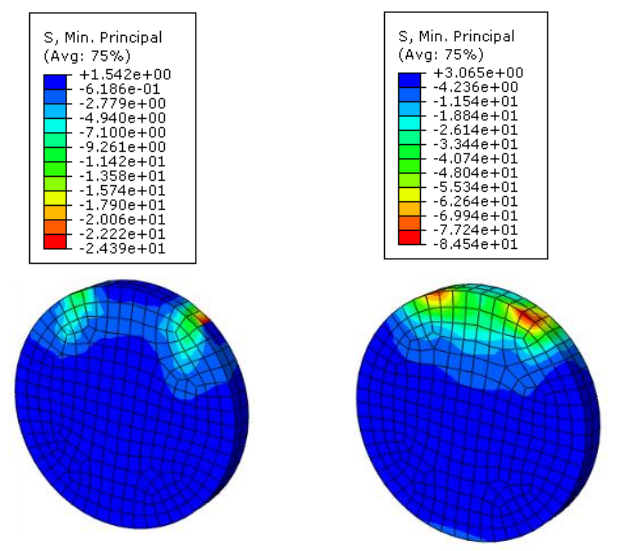

(b) Concrete at connection

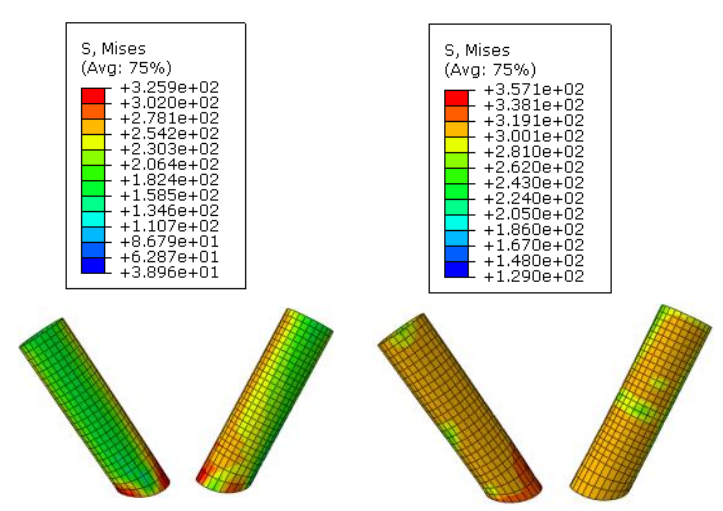

(c) Brace tubes

Fig. 7. Stress development along the components

Although the stress rises significantly over time, yield area at the connection remains almost the same. It can be understood that the existence of core concrete helps release the stress and delays the failure of the steel chord tube. For the inner concrete, only the outer surface crushes due to excessive stress, whereas 
the inner layers stay almost unaffected (Fig. $7 b)$. This proves that the concrete does not actively contribute directly for the loadcarrying, however, it significantly retards the yield propagation throughout the joint through effective stress redistribution. In contrast, the yield region in the hollow brace tubes expands significantly while the maximum stress does not rise over time, as shown in Fig. 7c. The brace region adjacent to the connection area yields first, gradually propagating to outer parts of the braces. The corresponding stress does not increase massively (325 to $357 \mathrm{MPa}$ ). Failure spreads gradually yet quickly along the hollow brace tubes with no infilled concrete.

\subsection{Full-range analysis}

\subsubsection{Typical full-range $\mathrm{N}-\Delta$ relation}

Full-range investigation on the behaviour of CFST K-joints under corrosion has been carried out using the FEA model. Fig. 8 shows the load $(N)$ versus displacement $(\Delta)$ relations of CFST $\mathrm{K}$-joints under two different conditions, i.e., 1) short-term loading and 2) long-term loading combined with corrosion. Two distinct curves were obtained to describe the $N-\Delta$ relations for these two cases.

1. Curve O-A-B-C in Fig. 8 displays the $N-\Delta$ relation under short-term loading before any corrosion occurred. The well-developed curve indicates that CFST K-joints has excellent ductility behaviour and the joint fails long after its ultimate capacity $\left(N_{\mathrm{u}}\right)$ is reached.

2. Curve O-A- $\mathrm{A}_{1}-\mathrm{B}_{1}-\mathrm{C}_{1}$ describes the $N-\Delta$ relation of CFST K-joint exposed to longterm loading and corrosion. The curve can be broadly divided into four characteristic stages.

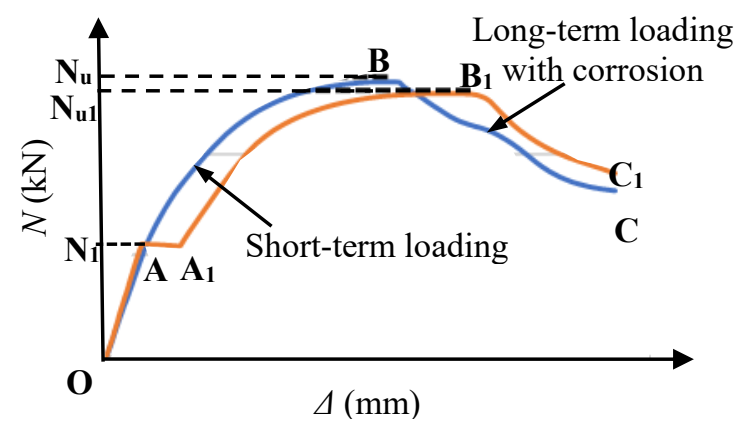

Fig.8. Typical $N-\triangle$ relation of CFST K-joints under corrosion
Stage I (O-A): service load $N_{1}$ is applied on the $\mathrm{K}$-joint before corrosion occurs. As the load in this stage is much less than the ultimate joint capacity, the load-displacement relation shows a linear response. Stage II (A-A $)_{1}$ : initial load $N_{1}$ is kept constant while uniform corrosion takes place, resembling the combined effects of sustained loading and corrosion in practice. A flat zone is obtained from the curve and the deformation grows up to point $\mathrm{A}_{1}$, which defines the time dependent effects of core concrete such as shrinkage and creep. Corrosion leads to stress redistribution between the concrete and steel, and also adversely affects the confinement of steel tube on the infilled concrete. Stage III $\left(\mathrm{A}_{1}-\mathrm{B}_{1}\right)$ : represents the continued loading stage up to the ultimate joint capacity $\left(N_{\mathrm{u} 1}\right)$. The CFST joint demonstrates elasto-plastic response and the drop of ultimate strength and stiffness compared to the curve $\mathrm{O}$ A-B-C is quite prominent. Stage IV $\left(B_{1}-C_{1}\right)$ : after the peak is reached at point $\mathrm{B}_{1}$, the deformation keeps growing while the axial load decreases. This plummet zone is dependent on the extent of corrosion and the composite action in the CFST chord. Effect of corrosion on this decreasing stage has been found to be moderate, whereas the influence of composite action has been obtained to be substantial. Overall, CFST K-joints exhibit excellent ductility when subjected to combined loading and corrosion compared with the reference CHS joints.

\subsubsection{Effects of different corrosion patterns}

Load-displacement relations have been obtained through full-range analysis of CFST $\mathrm{K}$-joints subjected to different corrosion situations, i.e., corrosion applied to chord or brace member individually as well as throughout corrosion along the joint (Fig. 9). It is evident from the graphs that chord corrosion has very moderate influence on the joint ultimate strength. A corrosion which reduces the chord thickness by $30 \%$ decreases the joint capacity by only $4 \%$ whilst the ductility of the joint remains excellent. This again proves that it is the hollow brace members that dominate the joint behaviour. The infilled concrete avoids local buckling and strengthens the chord, achieving a brace failure mode and leading to more ductile joint behaviour.

However, when the brace members are corroded, strength of the joints reduces dramatically. For a brace thickness loss of $30 \%$ 
due to corrosion exposure, a joint capacity reduction of around $30 \%$ is noticed. A significant deterioration of ductility is also perceived, the joint reaches maximum strength at around $18 \mathrm{~mm}$ chord displacement, compared to $35 \mathrm{~mm}$ when only chord is corroded. The throughout corrosion is found to be almost similar to the brace only corrosion. This indicates that regardless of the boundary conditions, hollow tubular brace is generally the most critical component of a CFST K-joint. When braces are exposed to corrosion, joint is vulnerable at much lower load and exhibits poor ductile behaviour.

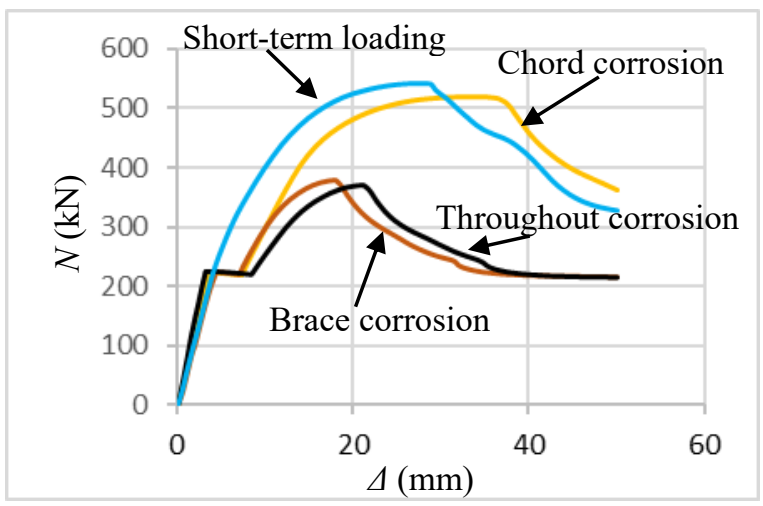

Fig.9. The $N-\Delta$ relations for different corrosion cases

\section{Conclusion}

Based on the limited research work in this paper, following conclusions can be obtained,

1) A FEA model considering the combined effect of loading and corrosion on CFST Kjoints was established and verified againest previous experimental results, good agreements were achieved.

2) Three typical modes were obtained for CFST K-joints under corrosion. Hollow braces were identified as the critical components of the joints, regardless of boundary conditions.

3) Propagation of stress development was thoroughly investigated. The confined concrete was found to be capable of preventing the spread of yield across the joint, which also enhanced the joint capacity and ductility.

4) Full-range analysis of CFST K-joints under combined loading and corrosion was performed. Corrosion in chord was found to have only moderate influence, whereas the joint behaviour was tremendously affected if brace was corroded.

\section{References}

[1] Nethercot DA. Composite construction. 2003, London: Spon Press.

[2] Han LH, Li W and Bjorhovde R. Developments and advanced applications of concrete-filled steel tubular (CFST) structures: members. Journal of Constructional Steel Research 2014; 100(1): 211-28.

[3] Uy B. Applications, behaviour and design of composite steel-concrete structures. Advances in Structural Engineering 2012; 15(9): 1559-71.

[4] Liew R, Lam D and Chung KF. Special issue on advances in steel-concrete composite structures foreword, Advances in Structural Engineering 2012; 15(9): 1 .

[5] Han LH, Hou C and Wang QL. Square concrete filled steel tubular (CFST) members under loading and chloride corrosion: Experiments. Journal of Constructional Steel Research 2012; 71: 11-25.

[6] Hou C, Han LH and Zhao XL. Full-range analysis on square CFST stub columns and beams under loading and chloride corrosion. Thin-Walled Structures 2013;68: 50-64.

[7] Hou CC, Han LH, Wang QL and Hou C. Flexural behaviour of circular concrete filled steel tubes (CFST) under sustained load and chloride corrosion. Thin-Walled Structures 2016; 107: 182-96.

[8] Han LH, Hua YX, Hou C and Wang QL. Circular concrete-filled steel tubes subjected to coupled tension and chloride corrosion. Journal of Structural Engineering 2017; 143(10): 04017134-1.

[9] Packer JA. Concrete-filled HSS connections. Journal of Structural Engineering, ASCE 1995; 121(3):458-67.

[10] Wardenier J, Packer JA, Zhao XL and Vegte GJ. Hollow sections in structural applications. 2010, Delft: Bouwen met Staal.

[11] Huang W, Fenu L, Chen B and Briseghella B. 'Experimental study on K-joints of concretefilled steel tubular truss structures'. Journal of Constructional Steel Research 2015; 107:18293.

[12] Han LH, Yao GH and Tao Z. Performance of concrete-filled thin-walled steel tubes under pure torsion. Thin-Walled Structures 2007; 45(1):24-36.

[13] Han LH, Li YJ and Liao FY. Concrete-filled double skin steel tubular (CFDST) columns subjected to long-term sustained loading. ThinWalled Structures 2011; 49(12):1534-43.

[14] Hou C, Han LH and Mu TM. Behaviour of CFDST chord to CHS brace composite K-joints: 
Experiments. Journal of Constructional Steel Research 2017; 135:97-109.

[15] Hou C and Han LH. Analytical behaviour of CFDST chord to CHS brace composite K-joints.
Journal of Constructional Steel Research 2017; 128:618-32.

[16] Melchers RE. The effect of corrosion on the structural reliability of steel offshore structures. Corrosion Science 2005;47: 2391-410. 